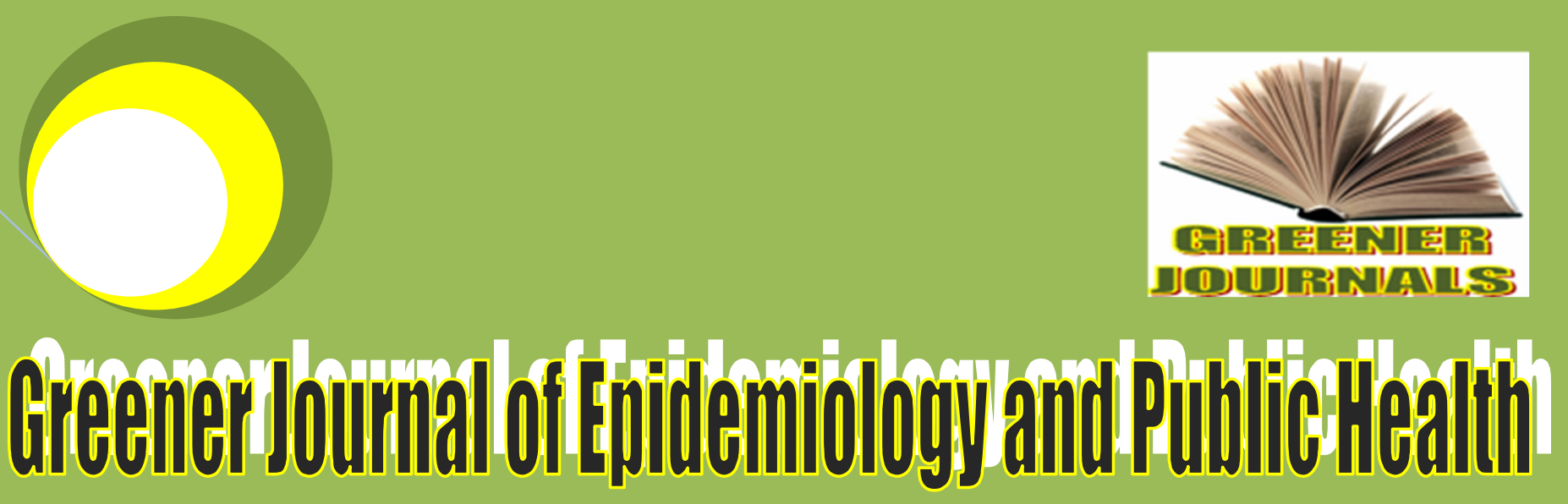

ISSN: 2354-2381

Submitted: $\mathbf{2 8 / 1 0 / 2 0 1 6}$

Accepted: 07/11/2016

Published: 29/11/2016

DOI: http://doi.org/10.15580/GJEPH.2016.3.102816178

A Retrospective Study of

Cases of Disease Condition of Large and Small

Ruminants Handle at the

State Veterinary Hospital

Maiduguri, Borno State,

Nigeria

By

Yusuf Audu

Jamila Dauda

Yusuf Madaki Lekko

Aliyu Aliyu Haruna

Mustapha Bamanga Umar 


\title{
A Retrospective Study of Cases of Disease Condition of Large and Small Ruminants Handle at the State Veterinary Hospital Maiduguri, Borno State, Nigeria
}

\author{
Yusuf Audu*1, Jamila Dauda², Yusuf Madaki Lekko1, \\ Aliyu Aliyu Haruna ${ }^{3}$, Mustapha Bamanga Umar ${ }^{4}$
}

\author{
${ }^{1}$ Department of Veterinary Medicine, Faculty of Veterinary Medicine, University of Maiduguri, P M B 1069, Maiduguri, \\ Borno State, Nigeria. \\ ${ }^{2}$ Department of Veterinary Public Health and Preventive Medicine, Faculty of Veterinary Medicine, University of \\ Maiduguri, P M B 1069, Maiduguri, Borno State, Nigeria. \\ ${ }^{3}$ Department of Veterinary Surgery and Theriogenology, Faculty of Veterinary Medicine, University of Maiduguri, \\ P M B 1069, Maiduguri, Borno State, Nigeria. \\ ${ }^{4}$ Veterinary Teaching Hospital, University of Maiduguri, P M B 1069, Maiduguri, Borno State, Nigeria.
}

${ }^{*}$ Corresponding Author's Email: yusufaudu99 @yahoo .com

\begin{abstract}
A retrospective study of cases of some diseases conditions handled and recorded at the state veterinary hospital Maiduguri from March, 2012 to April, 2016 was conducted. Cases of diseases conditions were selected based on consistency of recorded history, clinical signs and treatments as well as their public health significance. These includes; Listeriosis, Mange, Peste des petits ruminantis (PPR), Urinary tract infections (UTI), Tetanus, Mastitis, Sheep pox, Goat pox and Dog bite cases. The frequency distributions of the cases were presented according to species, year and months. Out of the total of 398 cases recorded, the occurrence of diseases and health condition was found to be highest in ovine with $243(61 \%)$ cases, while caprine and bovine has $153(38 \%)$ and $2(0.5 \%)$ cases respectively. Mange and dog bite cases were found to be highest and lowest with $111(28 \%)$ and $11(3 \%)$ cases respectively. Highest and lowest number of cases were recorded in 2015 and 2013 with $178(45 \%)$ and $35(9 \%)$ cases respectively. Similarly, the study showed that the months of March and August has the highest and lowest number of recorded cases of $62(16 \%)$ and 13 $(3 \%)$ respectively. This study showed that sheep were frequently presented to the hospital for treatment than goats and cattle, this may be due to their high market value, ease of handling and for religious festivities. The high number of cases recorded in $\mathbf{2 0 1 5}$ may be due to increased awareness of the hospital location and services provided by the hospital through the use of mass media at that time, while the low number of cases may be due to the lost of large volume of recorded cases for up to 5 months (May-September) couple with the insecurity situation of the town at that time. Disease occurrences during the dry season (March) tend to rise, this may be associated with inadequate pasture which may lead to starvation and reckless scavenging of food, and the available pastures tend to have lost their nutritive value.
\end{abstract}

Keywords: Retrospective study, large and small ruminants, disease conditions, Maiduguri.

\section{INTRODUCTION}

Nigeria is blessed with abundant livestock resource (Aliyu et al., 2005). A greater percentage (40-60\%) of small and large ruminant population is concentrated in the North eastern part of Nigeria (Aliyu et al., 2005). Sheep, goat and cattle are known to serve as source of animal protein, skin, manure, income and some cultural values (Tefera et al., 2009). This economic advantage is primarily associated with their ease of handling as it favors small scale investment, minimum risk of loss and high reproductive efficiency (Omoike, 2006). Factors affecting livestock production in sub Saharan countries includes diseases, poor management and lack of proper breeding policies (Adebowale, 2012). These have been observed as major constraints to livestock production in Nigeria (Ogbaje et al., 2012). Prevalence and intensity of pathogenic infections are often seasonal. This could be linked to changes in the host immunity or increase in the preponderance of either the pathogen or vector or both (Nelson et al., 2002). The knowledge of the pattern of disease occurrence is important as it suggests period of likely outbreak. It also helps in planning towards ensuring proper preventive measures (Thrusfield, 2005). This study was designed to determine the distribution and pattern of some diseases and health condition of sheep, goat and cattle encountered at the State Veterinary Hospital Maiduguri, over a period of four years (2012-2016). 


\section{MATERIALS AND METHODS}

\section{Study Area}

The study was conducted in Maiduguri, the capital city of Borno State in the Northeastern terrain of Nigeria. The city lies on an altitude of $354 \mathrm{~m}$ and is located between latitudes $10.2^{\circ} \mathrm{N}$ and $13.4^{\circ} \mathrm{N}$ and longitudes $9.8^{\circ} \mathrm{E}$ and $14.4^{\circ} \mathrm{E}$. The two dominant seasons are the wet (June to September) and the dry (October to May) seasons. Temperature ranges from $13-41^{\circ} \mathrm{C}$. Annual rainfall is at $9-198 \mathrm{~mm}$ and sunshine of $7-9$ hours/day. Relative humidity varies between 19 to $78 \%$ and remains at $45 \%$ during the wet season (Mayomi and Mohammed, 2014). The State Veterinary Hospital (also called the Sen. Ali Sherriff Veterinary Hospital) is located at the center of the city and is the only state owned veterinary hospital in Maiduguri. Sheep, goats and cattle in Maiduguri are kept under semi intensive management system.

\section{Study Subjects and Case Definition}

Sheep, goats and cattle presented for routine medical checkup and those that were apparently sick formed the study subjects. The cases of some diseases and other health conditions considered in this study were based on consistency of recorded history, clinical signs and treatments as well as their public health relevance. These includes; Listeriosis, Mange, Peste des petits ruminantis (PPR), Urinary tract infections (UTI), Tetanus, Mastitis, Sheep pox, Goat pox and Dog bite cases. The animals were examined by qualified veterinarians and diagnoses were made based on physical examinations and/or laboratory findings.

\section{Statistical Analysis}

The data generated were entered and managed in MS excel worksheet. The data were analyzed and summarized in tables and charts using descriptive statistics. The occurrence of diseases and other health conditions diagnosed was calculated using percentages.

\section{RESULTS}

Out of the total of 398 cases recorded, the occurrence of diseases and health condition was found to be highest in ovine with $243(61 \%)$ cases, while caprine and bovine has $153(38 \%)$ and $2(0.5 \%)$ cases respectively (Table 1). Mange and dog bite cases were found to be highest and lowest with $111(28 \%)$ and $11(3 \%)$ cases respectively. Highest and lowest number of cases were recorded in 2015 and 2013 with 178 (45\%) and 35 (9\%) cases respectively (Table 3). Similarly, the study showed that the months of March and August has the highest and lowest number of recorded cases of $62(16 \%)$ and $13(3 \%)$ respectively (Table 2), suggesting that clinical cases encountered during the dry season was more than that of wet season.

Table 1: Distribution of disease conditions recorded by species

\begin{tabular}{|l|l|l|l|l|}
\hline Diseaseconditions & Caprine & Ovine & Bovine & Total (\%) \\
\hline Listeriosis & 15 & 43 & 0 & $58(14.6)$ \\
\hline Mange & 24 & 85 & 2 & $111(27.9)$ \\
\hline PPR & 61 & 26 & 0 & $87(21.7)$ \\
\hline UTI & 4 & 18 & 0 & $22(5.5)$ \\
\hline Tetanus & 7 & 19 & 0 & $26(6.5)$ \\
\hline Mastitis & 20 & 20 & 0 & $40(10.1)$ \\
\hline Sheep pox & 0 & 27 & 0 & $27(6.8)$ \\
\hline Dog bite & 6 & 5 & 0 & $11(2.8)$ \\
\hline Goat pox & 16 & 0 & 0 & $16(4.0)$ \\
\hline Total $(\%)$ & $153(38.4)$ & $243(61.1)$ & $2(0.5)$ & 398 \\
\hline
\end{tabular}




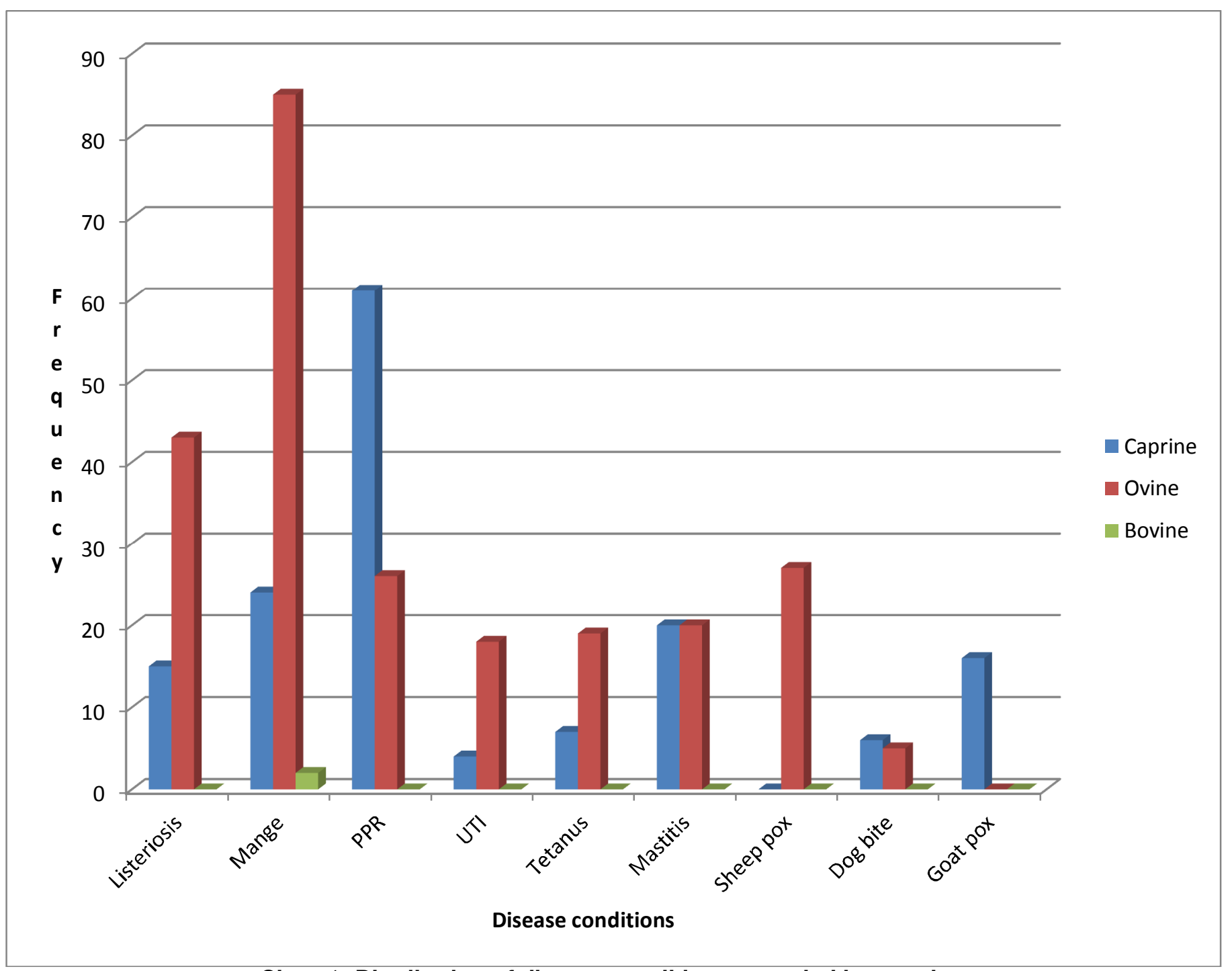

Chart 1: Distribution of disease conditions recorded by species

Table 2: Distribution of disease conditions recorded by months

\begin{tabular}{|l|l|l|l|l|l|l|l|l|l|l|l|l|l|}
\hline $\begin{array}{l}\text { Disease } \\
\text { conditions }\end{array}$ & JAN & FEB & MAR & APR & MAY & JUN & JUL & AUG & SEP & OCT & NOV & DEC & TOTAL (\%) \\
\hline Listeriosis & 7 & 7 & 7 & 10 & 3 & 2 & 2 & 2 & 3 & 7 & 4 & 4 & $58(14.6)$ \\
\hline Mange & 13 & 9 & 12 & 10 & 5 & 7 & 5 & 5 & 10 & 15 & 10 & 10 & $111(27.9)$ \\
\hline PPR & 9 & 8 & 17 & 9 & 15 & 9 & 4 & 0 & 4 & 3 & 3 & 6 & $87(21.9)$ \\
\hline UTI & 1 & 0 & 4 & 2 & 3 & 1 & 1 & 2 & 4 & 1 & 1 & 1 & $22(5.5)$ \\
\hline Tetanus & 0 & 3 & 3 & 0 & 5 & 0 & 3 & 1 & 2 & 4 & 4 & 4 & $26(6.5)$ \\
\hline Mastitis & 5 & 1 & 8 & 4 & 1 & 1 & 4 & 1 & 4 & 5 & 4 & 4 & $40(10.1)$ \\
\hline Sheep pox & 1 & 1 & 5 & 5 & 3 & 3 & 0 & 1 & 1 & 2 & 1 & 1 & $27(6.8)$ \\
\hline Dog bite & 1 & 4 & 1 & 1 & 0 & 1 & 0 & 0 & 0 & 1 & 1 & 1 & $11(2.8)$ \\
\hline Goat pox & 1 & 1 & 5 & 3 & 1 & 2 & 1 & 1 & 0 & 0 & 0 & 0 & $16(4.0)$ \\
\hline & 38 & 34 & 62 & 44 & 36 & 26 & 20 & 13 & 28 & 38 & 28 & 31 & \\
Total $(\%)$ & $(9.55)$ & $(8.54)$ & $(15.58)$ & $(11.06)$ & $(9.05)$ & $(6.53)$ & $(5.03)$ & $(3.27)$ & $(7.04)$ & $(9.55)$ & $(7.04)$ & $(7.89)$ & 398 \\
\hline
\end{tabular}




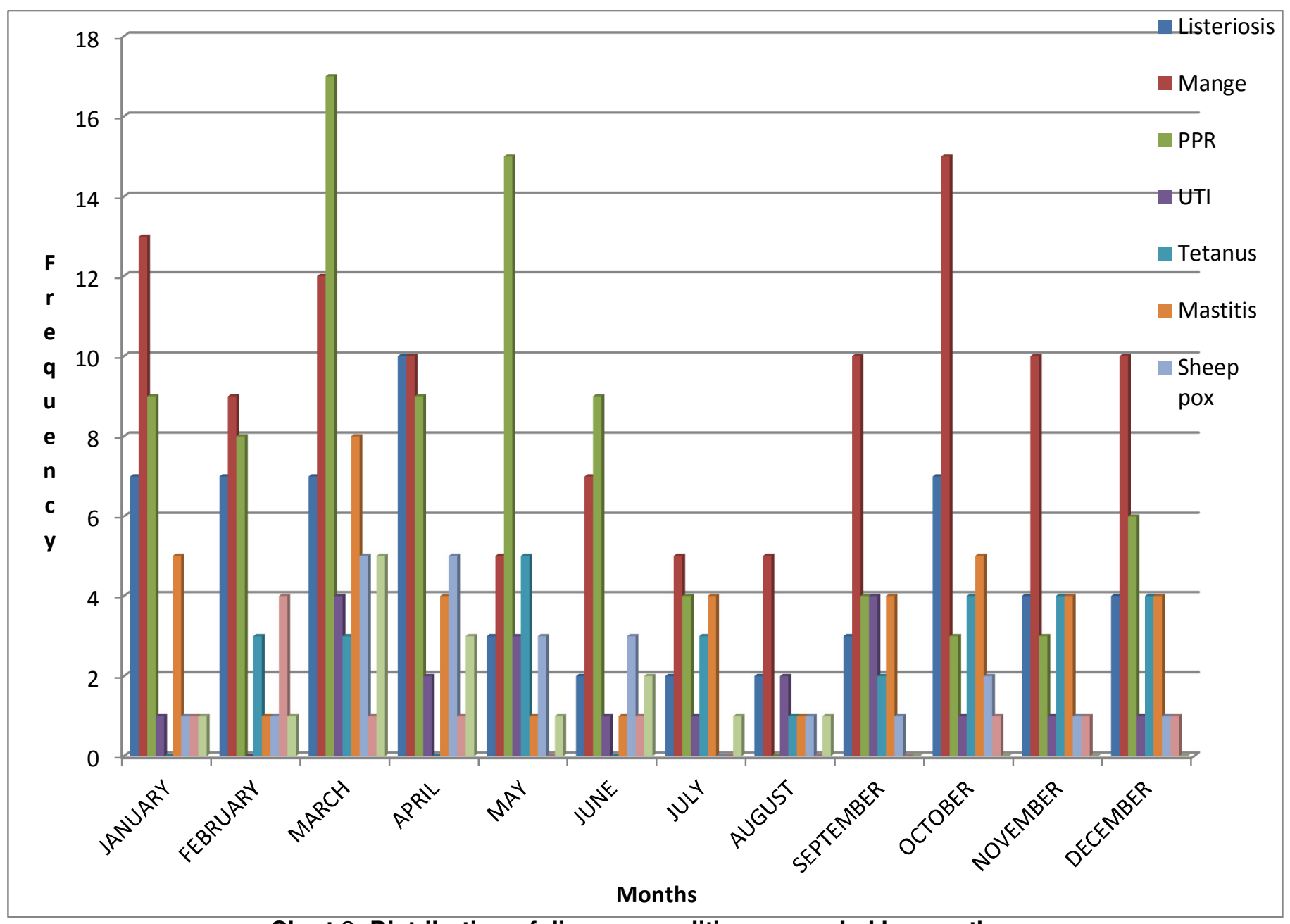

Chart 2: Distribution of disease conditions recorded by months

Table 3: Distribution of disease conditions recorded by year (2012-2016)

\begin{tabular}{|l|l|l|l|l|l|l|}
\hline $\begin{array}{l}\text { Disease } \\
\text { conditions }\end{array}$ & 2012 & 2013 & 2014 & 2015 & 2016 & TOTAL $(\%)$ \\
\hline Listeriosis & 6 & 7 & 17 & 18 & 10 & $58(14.6)$ \\
\hline Mange & 14 & 18 & 15 & 54 & 10 & $111(27.9)$ \\
\hline PPR & 6 & 2 & 23 & 45 & 11 & $87(21.9)$ \\
\hline UTI & 3 & 0 & 4 & 11 & 4 & $22(5.5)$ \\
\hline Tetanus & 6 & 0 & 4 & 13 & 3 & $26(6.5)$ \\
\hline Mastitis & 5 & 4 & 11 & 14 & 6 & $40(10.1)$ \\
\hline Sheep pox & 3 & 1 & 5 & 12 & 6 & $27(6.8)$ \\
\hline Dog bite & 3 & 3 & 1 & 4 & 0 & $11(2.8)$ \\
\hline Goat pox & 1 & 0 & 5 & 7 & 3 & $16(4.0)$ \\
\hline Total $(\%)$ & $47(11.8)$ & $35(8.8)$ & $85(21.4)$ & $178(44.7)$ & $53((13.3)$ & 398 \\
\hline
\end{tabular}




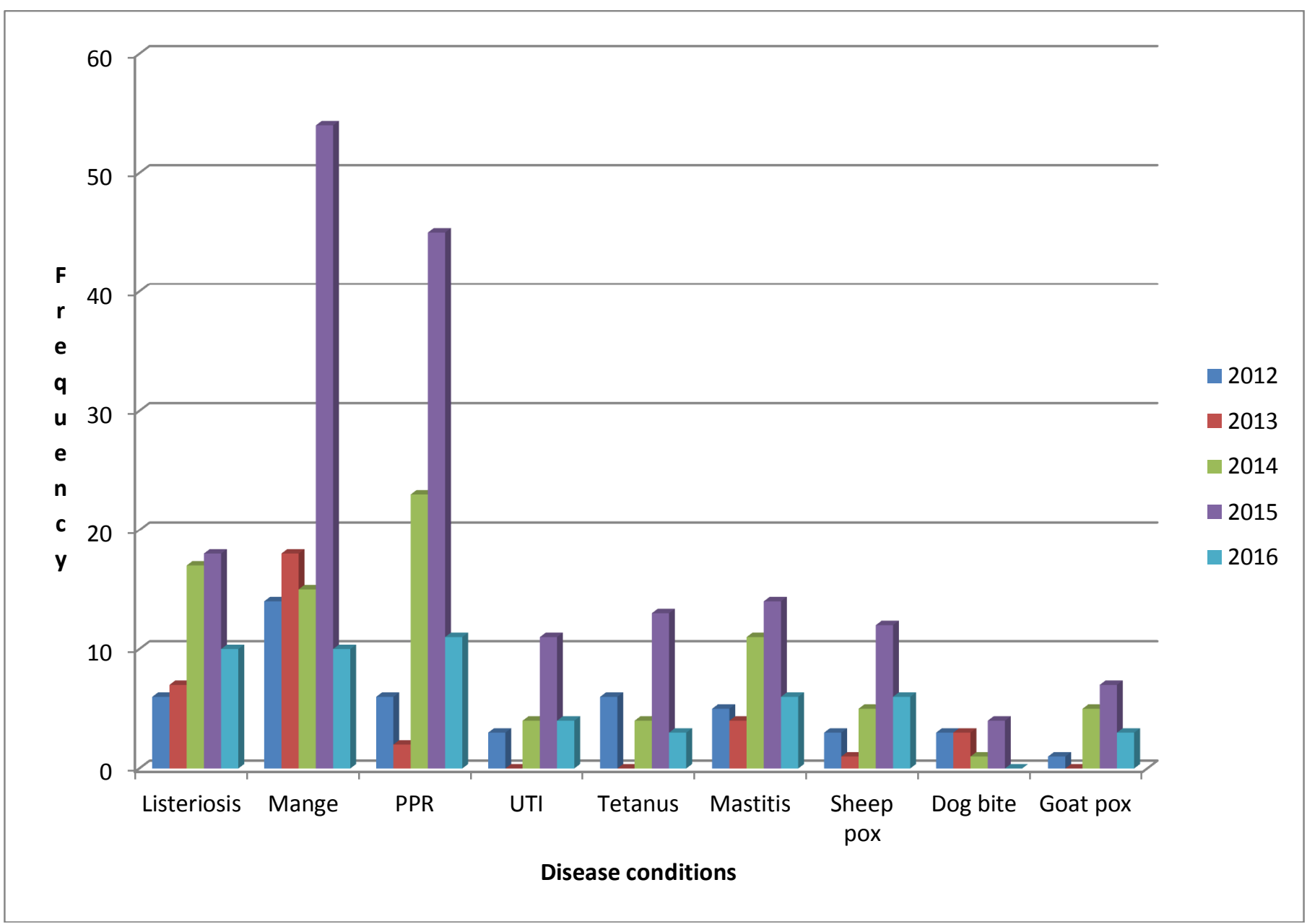

\section{Chart 3: Distribution of disease conditions recorded by year (2012-2016)}

\section{DISCUSSION}

The study showed that sheep were frequently presented to the hospital for treatment than goats and cattle. This may be due to the fact that animal owners in the study area keep sheep because of their high market value compared to goats and ease of handling compared to cattle (Aliyu et al., 2005) or for religious festivities. However, the fewer goats presented to the hospital for treatment might be due to their hardy nature or because they are resistant to common diseases, especially in the area where they are kept (Peacock, 1996). Higher number of cases was observed in the year 2015 and the least was observed in the year 2013. The high number of cases may be due to increased awareness of the hospital location and services provided by the hospital through the use of mass media at that time. Moreover, there is an increasing trend of awareness campaigns run by the government/state strategic bodies that results the improvements in livestock production and disease management (Buhari et al., 2015). The low number of cases may be due to the lost of large volume of recorded cases for up to 5 months (May-September) couple with the insecurity situation of the town at that time. The nature of diseases in sheep, goats and cattle in Maiduguri is similar during the years investigated. This may be due to management system thereby predisposing these animals to similar clinical diseases and disorders. It has been pointed out that animals managed under semi intensive system are predisposed to diseases and other disorders as compared to those managed under intensive system of management (Aliyu et al., 2005). This is further compounded by extremes of weather conditions and other environmental factors that impair the innate or adaptive resistance of these animals and thus increase their susceptibility to these diseases and disorders (Kamar et al., 2015). Mange presents itself as the most common disease condition in both sheep and goats. Environmental factors such as presence of mites and poor management system tenable in Maiduguri may predispose sheep and goats to Mange. It is common to see livestock roaming freely within most parts of the city lying on filthy surface which may be potential ground for ecto-parasitism. To plan an effective control program, a periodic surveillance of the prevalence of diseases and other health conditions in Maiduguri and associated risk factors that influence their transmission is required. 
Disease occurrences during the dry season tend to rise. This may be associated with inadequate pasture which may lead to starvation and reckless scavenging of food. The available pastures tend to have lost their nutritive value. It is thus evident that this condition affects animals and this lack of nutrients during such seasons impairs the ability of animals to mount an immune response to fight infections.

\section{CONCLUSION}

This study has shown that infectious diseases are the frequently encountered disorders in sheep, goats and cattle in Maiduguri. These cases were mostly observed during dry season. It is therefore recommended that animal owners and health service providers should provide and maintain available drugs, vaccines and equipment necessary for the management of these frequent clinical diseases and other health conditions. The need to carryout similar studies in other parts of the State and on other livestock diseases will be worthwhile as this will elucidate on the temporal distribution of diseases affecting livestock within the State. It is also recommended that vaccination against common viral diseases like PPR in the area be carried out routinely.

\section{COMPETING INTEREST}

The authors has none to declare

\section{AUTHORS CONTRIBUTIONS}

Yusuf Audu conceived the idea and prepare the initial draft, Jamila Dauda and Yusuf M. lekko collected and analyzed the data, Aliyu A. Haruna and Mustapha B. Umar revised the initial draft and prepare the final draft

\section{ACKNOWLEDGEMENT}

The authors are grateful to the management of the Borno State Veterinary Hospital, Maiduguri for accessing their hospital records.

\section{REFERENCE}

Adebowale OAL (2012). Dynamics of ruminant livestock management in the context of the Nigerian Agricultural System. In: Livestock Production (Eds. Khalid Javed). Intech. USA. ISBN978-953-51-0814-6. pp 61.

Aliyu MM, Bukar MM, Zira AB (2005). Occurrence of small ruminant lameness in Maiduguri and its environs. Sokoto J. Vet. Sci. 6(1): 1-4.

Buhari HU, Saidu SNA, Mohammed G, Raji MA (2015). Knowledge, attitude and practices of pastoralists on bovine brucellosis in the north senatorial district of Kaduna state. Nigeria. J. Anim. Health Prod. 3(2): 28-34.

Kamar D, Mehdi E, Chafiqa L, Ouafaa FF (2015). Bluetongue virus in Morocco from 2004 2012. J. Anim. Health Prod. 3(3): 48-53.

Mayom I, and Mohamed IA (2014): A decade of assessment of Maiduguri Urban expansion (2002-2012): Geospatial approach. Global J. Human Sci. B. 14 (2): 1.0

Nelson JR, Demas EG, Klein LS, Kriegsfeld JL (2002). Seasonal patterns of stress, immune function and disease. 1st ed. Cambridge University Press, Cambridge, UK. http://dx.doi. org/10.1017/cbo9780511546341

Ogbaje Cl, Ajogi I, Ofukwu R (2012). Disease and conditions of food animals mostly encountered in Zaria Abattoir in Northern Nigeria. J. Vet. Adv. 2(7): 402-406.

Omoike A (2006). Prevalence of disease among sheep and goats in Edo State, Nigeria. J. Agri. Social Res. 6(2): 2331.

Tefera M, Batu G, Bitew M (2009). Prevalence of gastrointestinal parasites of sheep and goats in and around Bedelle South Western Ethiopia. Internat J. Vet. Med. 8(2):1-3.

Thrusfield M (2005). Veterinary epidemiology 3rd Edition, Oxford: Black Science Ltd. Pp 228-246.

Cite this Article: Audu Y, Dauda J, Lekko YM, Haruna AA, Umar MB (2016). A Retrospective Study of Cases of Disease Condition of Large and Small Ruminants Handle at the State Veterinary Hospital Maiduguri, Borno State, Nigeria. Greener Journal of Epidemiology and Public Health, 4(3): 055-060, http://doi.org/10.15580/GJEPH.2016.3.102816178 